\title{
Study on Human Resource Reform in the Digital Transformation
}

\author{
Zhao Lei ${ }^{1}$, Yang Jing ${ }^{2}$ \\ 1. China Water Resources and Hydropower Research Institute, China \\ 2. Datang Environmental Industry Group, Co., Ltd., China \\ *Zhaolei_cdte@163.com \\ *Yangjing021@126.com \\ KeyWords: Human resource management; Standardization; Digitization
}

\begin{abstract}
As the digital technique symbolized with big data and cloud computing, the digital revolution is currently under stormrise worldwide, and a great number of enterprises are trying to embrace new business environment through digital transformation. Under such circumstances, the business model is facing revolutionary changes, so the human resource department, as one strategic business partner, is rapidly changing, and positively developing the digital and standardized working environment. This paper has discussed about the necessity, meaning and problems to carry out the digital and standardization transformation of human resource from many aspects and put forward some suggestions and solutions.
\end{abstract}

\section{Introduction}

As one of the most important parts of business management, the human resource management (referred to as HRM hereinafter) plays an essential role in the business operation and long-term development. In recent years, new digital technologies such as big data and cloud computing, etc. are emerging, which has brought challenges to the traditional HRM model. How to combine the concepts of digitization and standardization with HRM and how will the HR departments find a proper way to carry out reform, change the traditional business model, optimize the business frame, create the digital working environment and finally establish the modern HRM model have become common problems facing every enterprise. Aimed at solving all the conflicts and difficulties in the process of digitization and standardization of current HRM, this paper has explored problems and put forward some suggestions, which hopefully will improve company's management level and efficiency and contribute a lot to the national economic development.

\section{Conflicts and Problems of HR Reform in the Digital Transformation Background}

There are some characteristics of the current HRM such as increasingly diverse organization structures, larger span of management in the actual operation, more frequent flow of talented people within a company and between companies, and higher requirements of the quantity demanded and promptness of personnel's basic information. Therefore, companies urgently need to establish a highly efficient HRM model in order to improve the linkage of HR information, reasonably use the scientific managing tools, standardize the HRM procedure, and to provide high-quality service to company's development strategy [1][2].

So far, a majority of enterprises have realized office automation, web based service of financial fund management, long-distance service of project management and other kinds of informational reform, and have developed in the direction of group business centralization. However, because of company's complex personnel structure, enforced policy of HRM work, and the diversity of professional skills of HR practitioners, the information construction of HRM falls far behind that of 
other parts. Specifically speaking, the current reform of HRM digitization and standardization is now facing problems resulted from the following aspects.

\subsection{Positioning Deviation}

For a long time, "focusing on production, yet neglecting management" occurring in companies have not been completely solved, so problems of inactive mechanism and non-standard management are now facing companies. Although the business scale is expanding, the economic benefit is still in stagnation due to these problems, which has become the internal factor that restricts enterprises' development. For now, the positioning of HRM system digitization of some companies is still limited to the electronization of current business workflow, but not positioned on the actual contents of HRM, which is to systematically collect, gather and analyze the human resource information through management under the historical background of big data, and to deeply act on strategic direction planning of human resource, optimization of organization structural construction, projects' leading team establishment, precise positioning of elites, planning and development of employees' career, and management of employees' training information, etc.

Because of the vague positioning, the current human resource information system doesn't have enough supporting data. The system only serves as the operational software of HRM department, but not interacts with the closely related financial information and production management system, which has caused that companies may tend to act behind closed doors in the limited analyzing capacity of the system [3]. Meanwhile, manager at different levels cannot deal with the office work flow, production and management procedure, and human resource service process at the same operating platform, so senior managing leaders will abandon all kinds of decision support system including human resource information system [4]. Although the information construction is now under constant improvement, still there exists offline work flow among the senior leaders, which increases the workload and cost while decreases working efficiency.

\subsection{Poor Integration}

In the traditional management model and information system, there are problems like decentralized internal system, poor horizontal integration, and stagnant longitudinal interconnection [5]. Therefore, the "lonely island" and "chimney" in the current digital information system severely affects the company's uniform control efforts. The fragmented business system causes inefficient information, lack of overall data planning and failure to be integrated into the complete management information platform. Separation from personnel planning to actual production, from annual budge to financial management, from human resource to other business systems results in that the relationship between different businesses or even the different works of same business is mostly independent, fragmented and segmentary, and difficult to realize the information sharing. Management personnel of different levels have difficulties in being informed of the complete daily human resource condition of the basic units.

Basic data are in want of efficient integration and has a lower level of standardization, in addition to which, it lacks the group and company-level data and working standard and standard business flow [6]. Therefore, information coding is not unified with multiple definition, and it's difficult to realize the interconnection and match between data. Besides, the low degree of the availability and integration results in the poorer portability of some outstanding subsystems, which causes the failure to realize the integration and promotion of business or to efficiently support company's business analysis [7].

\subsection{Lower-level Standardization of Data and Business Process}

The traditional HRM model focuses more on the management and control of specific business and doesn't have thorough understanding of the characteristics of actual production process, the 
increment of company brought by human resource, and the management of the labor cost caused by human resource itself. Therefore, the traditional HRM model has weaker management and control ability and cannot reasonably allocate the scarcity cost to the control center of company's total cost. Data in the management process are relatively static. The traditional model has less analysis functions, inefficient decision support and corresponding management and control ability, so the decision process relies more on the already-learned experience, and the company's management level depends more on the quality of managing personnel with higher uncertainty [8].

Data in the system have a lower level of standardization, in addition to which, it lacks the group and company-level data and working standard and standard business flow. Therefore, information coding is not unified with multiple definition, and it's difficult to realize the interconnection and match between data. Besides, the low degree of the availability and integration results in the poorer portability of some outstanding subsystems, which causes the failure to realize the integration and promotion of business or to efficiently support company's business analysis.

\section{Significance of the Standardization Reform of HR in the Digital Transformation}

The appearance of digitization is very important to the business transformation at present. In the past, it was a habit for HR to use the trends over past years to predict the future adjustment, which was progressive optimization. However influenced by the digital transformation, the complete business model has changed, and the infinite imaginary space of HR makes it able to rapidly carry on innovation and exploration.

In the face of future exploration, HR needs to consider the system innovation from aspects of two basic disciplines. The first one is value creation, which means measures taken in HR should create better business value; the other one is effectiveness improvement - if the new HR measures can help company to improve benefits."

The HR digital management information platform is a set of centralized information system, and company's management procedure can be organically connected with information technology, which can help to realize personnel's whole life cycle management from on-boarding process approval, daily personnel and salary dispatching management to leaving the company; besides, it can also realize the whole operational process management from personnel management, salary management, talent training management, real time budget control and cost management, etc [9]. By clarifying responsibilities, the business process can be regular and standard; by applying the flexible and powerful workflow technology, fixed business process can be adopted and internal control and warning can be realized, which helps to provide the basis for the efficient control of different management levels, to restrict the arbitrariness and to strengthen the company's internal control. At the same time, changing personnel's working mode, ideas and behavior habits may help people get rid of tedious work to do creative work, and to increase working efficiency, achieve scientific decision and improve company's whole efficiency.

\subsection{An Irresistible Trend of Company Adapting to the Economic Developing and Information-Based Society}

Previously, some companies adopts monopoly management at their early developing stage, so they were lacking in management, and the weak internal management system and business system were common problems. The opening of markets after joining in WTO has introduced advanced management concepts, methods and techniques, but it is a big challenge to companies and makes them carry out management model transformation.

As the enterprise scale enlarges, higher requirements have been put forward about the monitoring systems of institutions, salary calculation and personnel situation of company and its subordinates 
[10]. The information system is required to provide the real time data support that is integrated, within the regional scale and able to guide the business operation, and it has become essential for companies to further enlarge the function and application range of information system to ensure company's breakthrough development. Through the application of the digital management information platform of human resource, on the one hand, the construction pace of the enterprise informatization will be greatly improved; on the other hand, the company will be able to establish an information platform, which can closely connects the external information resource with the internal one, in order to make sure that companies can make quick and scientific decisions in the fierce competition.

\subsection{Necessity for the State to Deepen the Reform of Enterprises}

With the state's rapid pace to deepen the enterprise reform and in the modern information society, the traditional management model is unable to satisfy the development steps of the world, and information has become the sixth energy, besides, using computers to collect information has become magic weapon of an increasing number of companies at home and abroad to improve the labor productivity, increase efficiency and get hold of the market initiatives.

By applying the modules of controlling project management, office automation and HRM, and information resource sharing, the HR digital management information platform can help to simplify the work contents, refine the granularity of the basic business data information, improve the readability and comparability of human HR information, and to enhance the control efforts of HR [11]. The effective monitoring and analysis of the flow status of HR inside and outside companies in the HR digital information system can realize the rigidity control of medium and long term budget of HR and the early-warning of the contract violation crisis. Thus it can also influence the understanding of different levels managers towards the operating conditions of companies so as to thoroughly alter the traditional way of managing, efficiently improve companies' capacity and effectiveness of management and control, and to deepen the enterprise reform.

\subsection{Improving Companies' Crisis Control, and Reducing Operating Costs}

The HR digital management information platform improves the consistency of data and realizes the simultaneity of logistics, capital flow and information flow through the integration of all kinds of internal and external business. By integrating the overall production process, the system collects personnel, fund, materials and other important resources to realize the cooperative production work and on-demand manufacturing, improve efficiency and resource integration, avoid wasting and to minimize companies' operational crisis. The real time data analysis is also able to help to integrate, modernize, standardize and automate companies operational procedures in aspects of HRM, salary management, reports and statistics, and talents development and management. Besides, owing to the real time data analysis, the constant increase in the quantity of data and information can timely and effectively provide information, based on which companies are able to make the best decision and to resist the periodic crisis.

\subsection{Standardizing Operation Process, and Improving Enterprising Management Model}

There are some urgent tasks like optimizing enterprising management model, integrating information application and informatization management innovation, and the $\mathrm{HR}$ digital management information platform is an integrated management model that combines the advanced management ideas with management methods, the internal resource with external environmental information. Based on the actual condition, this platform integrates and optimizes the business process and enterprise resource allocation, and breaks the long-established management model, all of which are helpful to provide an integrated, effective and highly efficient information management system. The business process will be more reasonable and minimize the rehandling. Meanwhile, the 
HR digital management information platform is capable to carry out flow control and data verification, so once an error within the control scale occurs, the system will automatically create verifying information, avoid low-level human error and improve the management efficiency with a clear direction.

Therefore, the necessity to carry on the HR digitization and standardization reform has been highlighted, and will become the development direction and inevitable choice of the modern HRM.

\section{Suggestions about the HR Standardization Reform in the Digital Transformation}

In the digitization and standardization reform, the adjustment and change of the human resource will become very rapid. In order to effectively improve enterprises' overall competitive forces and sustainable development levels, the strategy needed is to construct the management model and design system blueprint to standardize the relevant business process based on the actual business situation and reviews of procedures. At the same time, on the basis of ensuring the modularization, standardization and functionization of the system construction, reduce personnel's workload, enhance the functions of data batch penetration, extraction, integration and processing, simplify the business operational process of HRM, and timely develop multi-operating platform, ensure the information is reliable and researchable based on the integrated system, solve all the problems in the reform process by taking all the effective measures and improve the final results.

\subsection{Properly Determining the Organizational Leadership and Personnel Allocation}

The final success of the HRM digitization and standardization reform needs the management personnel at different levels to pay high attention, clarify the staff who are responsible for the project and unify the coordination and promotion. Three parties - HR departments, Information departments and technology programmers need to work together and cooperate closely, and all the branches and subsidiaries also need to participate entirely into the project construction in accordance with the headquarter's unified progress, in addition to which, persons in charge of HR departments at different levels must ensure the efficient cooperation and organization in the whole process, and provide guarantee from aspects of resource and organization. Besides, we need to pay much attention to the effective operation after the system come into effect in the future, strengthen the building of the ranks of HR information technology, draw up a reasonable talent introduction plan, cultivate the inter-disciplinary talents who are great at both business and information technology, and form a high-quality and high-level HR informatization professional force. The training work of the whole team and various kinds of users should also be ensured in every level of the project promotion to guarantee enough training time and achieve good training results.

\subsection{Properly Solving the Problem of Functional Positioning of System Modularization}

Whether the HRM information system can be successfully applied depends much on the reasonable functional positioning. The HR digitization and standardization reform must be based on the actual business situation, grasp the principal contradiction, and focus on the key part of management and control. Besides, adhere to the principles of overall planning and step-by-step implementation, divide the application system according to the quality of the relationship between the connected functional modules and the business relevance, integrate the related and similar systems, decrease the overall complexity of the system, realize the function of one of and more than one of the basic functional modules such as organization management, personnel management and salary management, and then improve and expand the optimization step by step. The companies' HRM digitization and standardization reform needs to be handled by the headquarters, and maintain the unified planning of both system planning and promotion. The system can be used to meet the 
demands of the management and control and analysis of headquarters and subsidiaries, establish the modularization business process through clarifying the management interfaces, responsibilities and work standard, improve the service level and professional quality of all the personnel from different levels, change personnel's existed working patterns, and transfer the focal point from business-oriented type to strategic decision making one. At the same time, select suitable business process in the system according to the actual situation, facilitate the basic unit to deeply be involved with the help of the reasonable and standard operation, improve the working efficiency and ensure the quality of data and information.

\subsection{Properly Solving the Problems of System Standardization}

Because of the diversity and complexity of the HRM work, inevitably there are conflicts between personal working habits and standardized business process. Therefore, a unified standard is very important and lays the solid foundation for the data statistics and analysis in the future. In the HRM digitization and standardization reform, according to the relevant requirements of the indicator system, analyze the characteristics of HR business, sort out the professional indicators, clarify the property of indicators including name, definition, calculation formula, statistical caliber, dimension and metric, categorize the indicators and form the classified documents of them in accordance with the business requirements. Standardization construction mainly consists of information technology standard, information management standard and information code standard. The information technology standard includes standard of basic terms and professional terms, standard of structured data, standard of data interchange and interconnects; the information management standard includes standardization of business process, management and maintenance process, standard template used to standardize the related industry and company's external reports; the management code standard includes the standard code compiling rules, methods and technology, classified code, the issuance and maintenance of standard code, etc.

The standard doesn't only involve the hard data criterion, but the soft process standard. The hard data criterion means that the system only supports one unified information code, which has been compiled according to the relevant standard of the state, industry and company, and if discrepancy occurs among standards, the highest standard should be followed. Using the unified standard is beneficial to the interconnection with the financial management and control platform and production management and control platform in the future. Staying firmly rooted in the present while looking ahead to the future means to consider both the current situation and the development requirements in the future, which helps to ensure the vitality, stability and expansibility, and the consistency of the hard data standard. As for the soft process standard, companies should hold meetings unscheduledly, maintain the unified standard level, establish and improve the work process of "establishment - using - feedback - maintenance and upgrading", and combine the standardization ideas into the daily work, provide the common value concepts and unified code of conduct for professional personnel, and truly realize the unification of process and standard.

\subsection{Properly Solving the Practical Problems of System Optimization}

Main causes of the poor situation of application in companies are the unfriendly system operation interface and imperfect function of statement formulating and inquiry, which are the most prominent problems according to users' feedback, and also are the main factors that restrict the system application. Besides, the general system data and quantity of users of the HRM information system in companies' branches and subsidiaries will be very huge, so in order to ensure the operational efficiency of the system, a team has been organized to deeply explore and properly solve the problems of system optimization. For integration, through full demonstration and reasonable design, the best solution has been invented to organically integrate the relevant information within the 
system, solve the problem of data interaction, and to maximize the sharing of various kinds of information resource.

\section{Conclusion}

In the process of HRM digitization and standardization transformation, in order to comprehensively upgrade the HRM quality, successfully realize the final purpose of HRM digitization and standardization, we need to follow the overall strategy of unified planning, top-level design, step-by-step implementation and constant improvement, emphasize the value, and refine the procedure of relevant business and eliminate the individual Information Island through business integration. Besides, we should also standardize the "weighting system" of management, realize the high-level resource sharing, and gradually enlarge the application range to bring the final purpose into reality.

\section{References}

[1] Fred Mayhew. Human service delivery in a multi-tier system: the subtleties of collaboration among partners[J]. JHHSA SUMMER, 2012:109-135

[2] Liu Xin. HRM Informatization Construction of Large-scale Company[J]. Electric Power Information Technology, 2011, 05:47-50.

[3] Carlos Martin-Rios. Why do firms seek to share human resource management knowledge? The importance of inter-firm networks[J]. Journal of Business Research, 2012,11:1-10

[4] Zhou Xue. Study on the Effective Approach of HRM Model of Group Company -- Based on the Case of Sinochem Group[J]. Human Resource Development of China, 2014, 07:71-77.

[5] Chih-Hsun Chuang, Shyh-jer Chen, Ching-wen Chuang. Human resource management practices and organizational social capital: the role of industrial characteristics[J]. Journal of Business Research,2013,66:678-687

[6] Wright P.M. , Boswell W.R.Desegregating HRM: A review and synthesis of micro and macro human resource management research[J]. Journal of Management, 2002, 28(3): 247-276

[7] Zhou Bo. Study on the Competitiveness of the State-backed Chinese Firm[D]. Jilin University, 2014.

[8] Fred Mayhew. Human service delivery in a multi-tier system: the subtleties of collaboration among partners[J]. JHHSA SUMMER, 2012:109-135

[9] Zhang Haonan. On the HRM Information Modernization Construction of Large-scale Company[J]. Economist, 2014, 10:222-224.

[10] Gao Shan, Li Zhe. Selection and Application of HRM Information System in Large-scale Company[J]. Management and Administration, 2012, 09:102-104.

[11] Huselid M.A.The impact of human resource management practices on turnover, productivity, and corporate financial performance[J]. Academy of Management Journal, 1995,38(3): 635-672 